\title{
CONTRADICTION TO CLINICAL IMMUNOLOGY. SUPPRESSION AND STIMULATION OF IMMUNE REACTIVITY IN PATHOLOGICAL PROCESSES
}

\author{
Vladimir M Zemskov ${ }^{1^{*}}$ | Andrey M Zemskov² | Victoria Neymann ${ }^{3}$ | Konstantin N \\ Pronko $^{4}$ | Alexander A Barsukov ${ }^{1}$ | Veronica A Zemskova ${ }^{2}$ | Maria N Kozlova ${ }^{1}$ \\ | Nadezhda S Shishkina ${ }^{1}$ | Valentina S Demidova ${ }^{1}$ | Alekseev Andrey A. ${ }^{1}$
}

\author{
${ }^{1}$ AV Vishnevski National Medical \\ Research Center of Surgery, \\ Moscow, Russia \\ ${ }^{2}$ Medical University named of \\ Burdenko, Voronezh, Russia \\ ${ }^{3}$ CEO VRFD SA, Shwitzerland \\ ${ }^{4}$ Facecontrol, Systems, Moscow, \\ Russia
}

\begin{abstract}
The analysis of literature data and our published results of examination of patients with a wide range of pathological processes was carried out. It has been established that polar changes in reactivity provoke the development of immune-dependent ones, which include primary and secondary immunodeficiencies, auto-aggressive and immunocomplex diseases, or immunoassociated purulent-inflammatory, nonspecific inflammatory lung diseases, cerebrovascular diseases, in which suppression and stimulation of reactivity is a pathogenetic mechanism for normalizing homeostasis, depending on the links of the immune system, doses of antigens, the initial state of protective functions, phases of the immune response, etc.

Keywords: Stimulation. Suppression. Immunodeficiency.

Copyright : (C) 2021 The Authors. Published by Innovative Journal. This is an open access article under the CC BY-NC-ND license (https://creativecommons.org/licenses/by-nc-nd/4.0/).
\end{abstract}

\section{1 | INTRODUCTION}

$\mathrm{D}$ iscussing the literature data and our studies of patients with various pathologies, it was possible to establish that the arising variations in immune reactivity induce immunedependent or immunoassociated diseases. With these pathologies, the resulting variations may turn out to be one of the most important pathogenetic links in maintaining the physiological balance of the immune
Supplementary information The online version of this article (https://doi.org/10.15520/ijmhs.v11i05.3 286) contains supplementary material, which is available to authorized users.

Corresponding Author: Vladimir M Zemskov AV Vishnevski National Medical Research Center of Surgery, Moscow, Russia

Email: arturrego@yandex.ru. 


\section{INNOVATIVE JOURNAL}

system. $^{1,2}$

\section{Diseases due to suppression of immune reactivity}

\section{Primary immunodeficiency states}

These diseases of a genetic nature, accounting for $0.05 \%$ of all immunodeficiency states, are divided into B-dependent, in which, on average, the function of B-lymphocytes is impaired by $50 \%$. There are violations of the humoral immune response, increased sensitivity to infections caused by extracellular parasites. The T-dependent form of the disease manifests itself on average at the level of $30 \%$ of disorders in the differentiation of T-lymphocytes into subpopulations, thymic functions. With combined immunodeficiencies, an average of about $10 \%$, a very high mortality is recorded, and with violations of the phagocytic system (on average 8\%), sensitivity to pyogenic microorganisms increases. With violations of the complement system, amounting to about $2 \%$, autoimmune diseases, recurrence of purulent infections are noted, sensitivity to gono- and meningococci increases. ${ }^{3}$

\section{Secondary immunodeficiency states}

These diseases are acquired under the influence of previous infections, somatic diseases of the liver, kidneys, pancreas, hormonal imbalance, improper lifestyle, adverse factors at home and at work, the use of drugs that suppress the immune system, the influence of ionizing radiation, protein starvation, protein metabolism disorders and others. ${ }^{4}$

\section{Clinical manifestations of immunodeficiency}

\section{Humoral immunity}

Immunoglobulins, especially $\boldsymbol{I} \boldsymbol{G}$, play a leading role in killing bacteria and other infectious agents, contribute to the implementation of the opsonizing effect, which is manifested by recurrent and chronic bacterial infections, including those caused by "weak" non-virulent pathogens. The respiratory organs, gastrointestinal tract, paranasal sinuses, and meninges are mainly affected.

Infections proceed with severe intoxication, often complicated by septicemia. However, antiviral immunity is impaired to a lesser extent. With IgMdeficiency in patients, the risk of developing severe meningococcal meningitis, complicated by sep- ticemia, repeated respiratory infections with the formation of bronchiectasis, increases. IgA deficiency is often asymptomatic, since it is overlapped by the formation of immune globulins of classes $M$ and G. Deficiency of specific antibodies of all classes is diagnosed by negative serological reactions with a reliably established etiology of the disease. Clinically manifests itself at the age of 3-6 months, is characterized by frequent respiratory infections, conjunctivitis, chronic sinusitis, bronchitis, chronic lung diseases with an outcome in bronchiectasis, pulmonary fibrosis.

\section{Cellular immunity}

Deficiencies of cellular immunity are manifested by the development of infections with intracellular parasitism of the pathogen, such as tuberculosis, viral infections, as well as leprosy, brucellosis, mycoses. With less severe deficits, persistent or frequent repeated viral infections develop more often, and more severe ones are manifested by mycoses or diseases caused by protozoa.

\section{Combined immunodeficiencies}

They are characterized by combinations of the clinic of humoral and cellular deficiencies and other immune disorders. Such combinations most often end in death already in the first year of a child's life. Combinations of pneumonia with infections of the gastrointestinal tract and skin caused by bacteria, viruses, fungi are typical. Infections are difficult, poorly amenable to therapeutic effects. Patients usually die from septicemia or malignant neoplasms.

\section{Phagocytic link of immunity}

In this case, the deficiency is manifested by a decrease in the number of phagocytes, in which neutropenia develops, a defect in chemotaxis, often indicated by the syndrome of «lazy» leukocytes, an imbalance in the absorption and metabolic capacity of cells, which is accompanied by the development of recurrent infections, microabscesses, suppression of the inflammatory cellular response.

\section{Diseases caused by activation of immune reactivity 3,4}

This compartment of pathology includes autoimmune diseases, which are characterized by the development of an immune response to antigens of their 


\section{CONTRADICTION TO CLINICAL IMMUNOLOGY. SUPPRESSION AND STIMULATION OF IMMUNE REACTIVITY IN PATHOLOGICAL PROCESSES}

own tissues. These pathological processes are based on excessive humoral and cellular immune responses that damage specific organs and tissues during the deposition of immune complexes on the vascular endothelium or through the activation of complement, inducing inflammation (vasculitis) with secondary damage to the target organ. In principle, autoimmune diseases are a special case of immunopathology.

Autoimmune diseases, consisting of about 80 names, are widespread in the human population, because in general, they affect up to $5 \%$ of the world's population. They are characterized by a prolonged polycyclic progressive recurrent course, persistent fever of the wrong type with chills, severe weight loss with trophic disorders, systemic damage to the connective tissue, suppression of the pathological process when using suppressors and its activation when using immunostimulants.

Autoimmune diseases are conventionally divided into three main types. Organ-specific, which are caused by autoantibodies and sensitized lymphocytes against one or a group of autoantigens of one organ, more often barrier-free, to which there is no natural (innate) tolerance. Non-organ-specific, in which, against the background of pre-existing tolerance, reactions to autoantigens of cell nuclei, enzymes of the cytoplasm, mitochondria, etc. are induced. Mixed ones include both of these mechanisms.

The mechanisms of autoimmune diseases, as we have already reported, ${ }^{5}$ are based on a variety of mechanisms: (1) a decrease in the suppressor activity of cells, (2) the appearance in the bloodstream of barrier "sequestered" antigens of the eye, gonads, brain, cranial nerves, (3) antigenic mimicry due to microbial antigens that have common determinants with "normal" antigens, (4) mutations and increased concentration of autoantigens in circulation, (5) modification of autoantigens by chemical agents, viruses, etc. with the formation of biologically highly active superantigens, (6) congenital deficiency Tcytotoxic suppressors, (7) decrease in apoptosis of T-helper cells that activate B-lymphocytes, (8) induction of expression of HLA-DR antigens on cells previously lacking them, (9) induction by viruses and other agents of modification of the activity of autoantigens-oncogenes, regulators of the production of cytokines and their receptors, (10) the formation of autoantibodies of the IgM class in the fetus to many components of autocells that do not eliminate from the body, accumulate with age and cause autoimmune diseases in adults, (11) the use of auto-aggressive drugs, for example, dopegitis, which causes hemolytic anemia, apressin systemic lupus erythematosus, sulfonamides periarteritis nodosa, pyrazolone and its derivatives, respectively, agranulocytosis, etc.

The key cell in the development of the pathogenic process is the autoreactive T-lymphocyte, which reacts to a specific autoantigen and then, through the immune cascade and the involvement of Blymphocytes, causes the formation of organ-specific autoantibodies.

Immunocomplex diseases are based on immune complexes, that is, the combination of an antibody with an antigen of an average mass, thrombotic capillaries, binding to complement, resulting in organ damage and the release or modification of active autoantigens.

Autoimmune and immunocomplex diseases include: (1) diseases with the presence of immune complexes, (2) idiopathic inflammatory processes, systemic lupus erythematosus, rheumatoid arthritis, ankylosing spondylitis, essential cryoglobulinemia and scleroderma, infections bacterial streptococcal, staphylococcal, mycoplasma, leprosy, (3) viral hepatitis, Dengue fever, infectious mononucleosis,

cytomegalovirus disease of newborns, parasitic infections - malaria, trypanosomiasis, toxoplasmosis, leishmaniasis, (4) renal diseases, acute glomerulonephritis, IgA nephropathy, renal transplantation, (5) hematological and neoplastic diseases, acute lymphoblastic and myeloid leukemia, Hodgkin's disease, 6) diseases dermatitis herpetiformis, pemphigus and pemphigoid. This group also includes (7) gastrointestinal Crohn's diseases, ulcerative colitis, chronic active hepatitis, (8) neurological diseases subacute sclerosing panencephalitis, amyotrophic lateral sclerosis, (9) pathology of the endocrine system Hosimoto's thyroiditis, juvenile diabetes, and, finally, (10) iatrogenic diseases - acute serum sickness, D-penicillamine nephropathy, drug thrombo- 


\section{INNOVATIVE JOURNAL}

cytopenia.

\section{The ratio of the increase and suppression of im- mune parameters in the pathogenesis of inflamma- tory diseases}

It is known that biological processes are subject to a certain variability, which has a physiological and pathological orientation. We postulate that changes within the range of significant

stimulation/suppression values by $0-33 \%$ of the studied parameters (rank III) are physiological insignificant $(\mathrm{P}>0.05)$, the rest are average (rank II) by 33$66 \%$ or significant (rank I ) by $>66 \%(\mathrm{P}<0.05)$ in both cases. ${ }^{6}$

\section{An overview of our published data ${ }^{7}$}

More than 120 people were under observation, suffering from three nosoforms of pyo-inflammatory diseases (PID)- exacerbation of deep pyoderma, chronic pyelonephritis, salpingo-oophoritis and nonspecific inflammatory lung diseases (NILD), in this case mixed and exogenous bronchial asthma, chronic obstructive for six groups of 20-25 people each. ${ }^{6}$

The statistical reliability of indicators from the normative level of healthy individuals was determined using parametric and non-parametric Student and Wilcoxon-Mann-Whitney tests, depending on the "normality" of the distribution of the studied parameters. Since the array of laboratory data, consisting of 28-30 markers and six groups of subjects was significant, methods of formalized mathematical assessment were used to interpret the variations in indicators. For this, laboratory parameters of patients were grouped according to five main links of immunity, which make up routine hematological (leukocytes, lymphocytes, mature and immature granulocytes, monocytes, erythrocyte sedimentation rate), cellular (T-cells, natural killer cells, their subpopulations), humoral (B-lymphocytes, immunoglobulins different classes, medium-weight molecules (MWM), circulating immune complexes (CIC), phagocytic (nonlymphoid cells with adhesion receptors, absorption and metabolic capacity of neutrophils), cytokine (pro- and anti-inflammatory cytokines). They were assessed using the rank method. $6,7,8$

A descriptive analysis of the indicators of patients with PID in the acute period established a general pattern consisting in an increase in hematological markers of inflammation against the background of lymphopenia, a decrease in the values of $\mathrm{T}$ dependent and imbalance of phagocytic markers, hyperimmunoglobulinemia, and accumulation of cytokines. In NILD, other features were found, indicating the activation of proinflammatory parameters in combination with anemia and lymphopenia, inhibition of the T-link of immunity and an increase in the formation of autoaggressive MWM and CIC, as well as in the disproportion in the absorption and metabolic capacity of phagocytes, pro- and antiinflammatory cytokines.

It follows from the table that with PID and NILD, the sum of laboratory parameters was significantly changed from the normative level of healthy individuals with a predominance of the increase vector over the suppressor one.

In a detailed analysis in patients with PID, hematological markers of inflammation and humoral defense increased significantly (rank I), and the cellular and phagocytic ones were significant, but with the average indicators of the ranks (rank II), they were suppressed. In NILD, all laboratory parameters grouped by links, with the exception of phagocytic, were moderately elevated (rank II), while cellular and phagocytic parameters were in a state of suppression, respectively. At the same time, the "increasing" potential in general for lung diseases was preferably high, and the variations in the T-dependent parameters were parity multidirectional (II and II ranks).

Thus, in the acute stage of inflammatory diseases of various origins, the formation of laboratory parameters multidirectional in the direction of increase/suppression, both separate and grouped by immunity links, was established, which should be taken into account when prescribing corrective effects to patients.

At the stage of remission, PID completely eliminated the suppressive one and retained a reliable amplifying dynamics of all five links of immunity. In patients with NILD, the initial character of immunopathology was practically preserved, manifested by the activation of hematological, cellular, humoral and cytokine markers with the simultaneous suppression of $\mathrm{T}$ dependent and phagocytic parameters. 
TABLE 1: Vector of predominant variations of the grouped indicators by the links of immunity in the acute period of diseases in the rank assessment

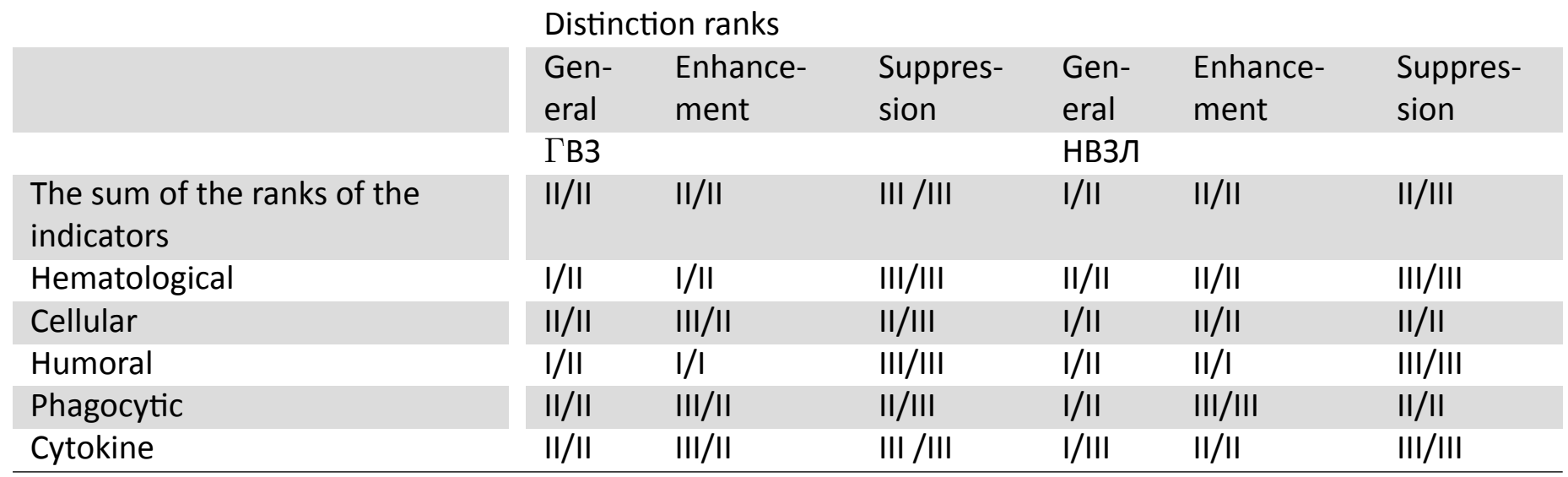

Legend: laboratory parameters for diseases in the stage of exacerbation/remission. I, II, III - ranks of changes (see test for decoding).

\section{The ratio of the increase and suppression of im- mune parameters in diseases with complex patho- genesis}

The subjects of the examination were patients suffering from multiple sclerosis in the stage of exacerbation and remission, patients with eight variants of cerebrovascular diseases with an increasing severity of hypertonic disease 1, 2, 3 (HD1, HD2, HD3), hypertensive crisis, acute hypertensive transient encephalopathy, transient ischemic attack, ischemic and hemorrhagic strokes. Patients suffering from viral hepatitis B and carriers of the HBS antigen (HBs$\mathrm{Ag})$ were also examined. The laboratory panel in different groups included 55 parameters: 6-9 hematological, 16-19 immune, 10-routine biochemical, 15-21 metabolic indicators of free radical oxidation of lipids and proteins, mechanisms of the antioxidant system. ${ }^{9}$ In patients using frequency analysis, the percentage grouped by methods of analysis of markers with 2-3 degrees of increase/suppression, summed them $(\Sigma)$, determined the gradient of the difference $[\Delta]$ (Table 2), performed the calculation of the coefficient of diagnostic value, which made it possible to establish signal markers of disorders. ${ }^{6,10}$

It was found that in the stage of exacerbation of multiple sclerosis there was a significant tendency to increase the total and all indicators grouped by research methods. With the stabilization of the pathological process, the indicated pattern leveled out, however, a residual increase in hematological mark- ers remained.

In cerebrovascular diseases, significant variations in the parameters began to be determined only with sufficient clinical severity of the pathology, starting from the third stage of hypertonic disease, and they were typical. With rare exceptions, this was a decrease in the values of hematological markers against the background of an increase in immune and routine biochemical parameters. Suppression of metabolic markers was additionally determined in ischemic stroke.

In cerebrovascular diseases, the composition of typical ISDFs (see Legend Table 3-4) was characterized by rather significant changes. They consisted of the following: (1) HD1 (hypertonic disease of increasing severity $1,2,3$, for an explanation of the formulas, see tables 2-4) $-\mathrm{NBTac}_{2}{ }^{-} \mathrm{IgA}_{2}{ }^{+}$ $\mathrm{Tc}_{2}{ }^{+}$, (2) GB2- $\mathrm{IgA}_{2}{ }^{+} \mathrm{NBTsp}_{2}{ }^{-} \mathrm{Tc}_{2}{ }^{+}$, (3) GB3$\mathrm{NBTac}_{3}{ }^{-} \mathrm{NK}_{2}{ }^{+} \mathrm{NPT}_{1}{ }^{-}$,(4) hypertensive crisis$\mathrm{NBTac}_{3}{ }^{-} \mathrm{NK}_{3}{ }^{+} \mathrm{DC}_{2}{ }^{+}$, (5) acute hypertensive encephalopathy- $\mathrm{NK}_{3}{ }^{+} \mathrm{NBTac}_{2}{ }^{-} \mathrm{SB}_{2}{ }^{+}$, (6) transient ischemic attack- $\mathrm{NK}_{3}{ }^{+} \mathrm{NBTac}_{2}{ }^{-} \mathrm{SB}_{2}{ }^{+},(7)$ ischemic stroke- $\mathrm{NK}_{3}{ }^{+} \mathrm{ARA}_{2}{ }^{-} \mathrm{SB}_{2}{ }^{+}$, (8) hemorrhagic stroke$\mathrm{NK}_{3}{ }^{+} \mathrm{IL}_{3}{ }^{+} \mathrm{SB}_{3}{ }^{+}$. Comparative analysis of the composition of the formulas revealed two regularities, which are that as the pathological process aggravated, metabolic ones begin to be introduced into the initial composition of exclusively immune signaling markers, and the ratio of increased and suppressed indicators in six cases out of eight was 
TABLE 2: Ratios of increasing and decreasing the values of laboratory parameters in patients with complex pathogenesis of diseases

\begin{tabular}{|c|c|c|c|c|c|}
\hline & \multicolumn{5}{|l|}{ Markers } \\
\hline & $\Sigma$ markers & $\begin{array}{l}\text { Hematologi- } \\
\text { cal }\end{array}$ & Immune & $\begin{array}{l}\text { Biochemi- } \\
\text { cal }\end{array}$ & Metabolic \\
\hline & $+/-/ \Delta$ & $+/-/ \Delta$ & $+/-/ \Delta$ & $+/-/ \Delta$ & $+/-/ \Delta$ \\
\hline Multiple sclerosis, exacerbation & $58 / 17 /+42 *$ & $89 / 0 /+83^{*}$ & $94 / 50 /+44^{*}$ & $36 / 0 /+36^{*}$ & $33 / 0+34 *$ \\
\hline Multiple sclerosis, stabilization & $54 / 42 /+13$ & $83 / 50 /+33^{*}$ & $69 / 69 / 0$ & $46 / 55 /-9$ & $7 / 0 /+7$ \\
\hline Hypertonic disease 1 & $15 / 16 /-1$ & $11 / 18 /-7$ & $25 / 19 /+6$ & $11 / 22 /-11$ & $10 / 0 /+10$ \\
\hline Hypertonic disease 2 & $26 / 18 /+8$ & $33 / 22 /+11$ & $38 / 25 /+13$ & $33 / 22 /+11$ & $14 / 10 /+4$ \\
\hline Hypertonic disease 3 & $20 / 20 / 0$ & $11 / 44 /-33^{*}$ & $31 / 25 /+6$ & $22 / 0 /+22^{*}$ & $14 / 14 / 0$ \\
\hline Hypertensive crisis & $24 / 20 /-4$ & $11 / 33 /-22^{*}$ & $50 / 31 /+19 *$ & $44 / 0 /+44^{*}$ & $14 / 10 /+4$ \\
\hline $\begin{array}{l}\text { Acute hypertensive } \\
\text { encephalopathy }\end{array}$ & $31 / 20 /+11$ & $11 / 27 /-16$ & $50 / 31 /+19 *$ & $33 / 0 /+33^{*}$ & $24 / 14 /+14$ \\
\hline Transient ischemic attack & $31 / 20 /+11$ & $11 / 22 /-22 *$ & $56 / 25 /+31 *$ & $44 / 0 /+44^{*}$ & $14 / 14 / 0$ \\
\hline Ischemic stroke & $33 / 33 / 0$ & $22 / 56 /-34^{*}$ & $50 / 31 /+19 *$ & $44 / 0 /+44^{*}$ & $\begin{array}{l}19 / 38 /- \\
19 *\end{array}$ \\
\hline Hemorrhagic stroke & $27 / 22 /+5$ & $22 / 67 /-45^{*}$ & $38 / 19 /+19 *$ & $55 / 0 /+55^{*}$ & $10 / 14 /-4$ \\
\hline Viral hepatitis B & $67 / 47 /+20^{*}$ & $57 / 29 /+28^{*}$ & $62 / 39 /+23 *$ & $60 / 30 /+30 *$ & \\
\hline Carrier HBS Ag & $37 / 33 /+3$ & $29 / 0 /+29 *$ & $\begin{array}{l}39 / 62 /- \\
37^{*}\end{array}$ & $30 / 10 /+20 *$ & \\
\hline
\end{tabular}

Legend: $\Sigma$ - sum of indicators, $\Delta$ - gradient of change in indicators with+\- significant increase/suppression of markers from the norm, * reliability of differences with $\mathrm{P}<0.05$, hypertonic disease $1,2,3$ - increasing severity of the disease

monotonous, like 2 to 1 .

In patients with variants of a productive viral infection (hepatitis B and carriage of HBs-Ag), a different pattern was established. In the first case, there was an increase in the content of T-cells, natural killer cells, regulatory subpopulations of lymphocytes, B-lymphocytes, immune globulins of the main classes, liver markers, granulocytes. In carriers of HBs-Ag, the content of natural killer cells increased, the spontaneous NBT test and eosinophils increased. Formalized analysis in hepatitis B showed a significant increase in total, hematological, immune and biochemical parameters, while in carriers of the Australian antigen increased hematological and biochemical markers, but decreased immune.

\section{The ratio of increase and suppression of key indi- cators for various diseases}

Table 3 provides information on the distribution of increased and decreased key parameters in patients with fourteen types of NILD and eleven PID, summarized in the immune system disorders formula 6,10 .
The data in Table 3 indicate that the individual spread of key markers according to the vector of changes from the normative level of healthy individuals turned out to be dependent on the pathogenesis of diseases. So, in patients with NILD, in general, there was a preferential suppression, respectively, $83.3 \%$ of indicators versus an increase of $16.7 \%$. With regard to PID, the data turned out to be opposite, since $41.1 \%$ of markers were suppressed with PID versus $58.3 \%$ increased $(\mathrm{P}<0.05)$.

In children born with asphyxia and in healthy children, the following ${ }^{11}$ results were obtained (Table 4).

The ratio of suppressed and increased from the norm key ISDF indicators in children from two groups (numbers are not shown in the table) turned out to be diametrically opposite. In children with asphyxia, the number of reduced markers was significantly [*$\mathrm{P}<0.05]$ greater $\left(70.0^{*} / 30.0^{*}\right)$ than increased markers, while in healthy children this ratio was opposite $(42.9 * / 57.7 *)$. Subsequent analysis showed that suppression of signaling markers turned out to be 


\section{CONTRADICTION TO CLINICAL IMMUNOLOGY. SUPPRESSION AND STIMULATION OF IMMUNE REACTIVITY IN PATHOLOGICAL PROCESSES}

\section{TABLE 3: Key immune disorders in certain diseases}

\begin{tabular}{|c|c|c|c|}
\hline Diseases & ISDF & Diseases & ISDF \\
\hline Acute pneumonia & $\mathrm{CD}_{2}{ }^{-} \lg \mathrm{M}_{2}{ }^{-} \lg \mathrm{A}_{2}^{-}$ & Acute and chronic pneumonia & $\mathrm{IL}_{3}{ }^{+} \mathrm{CIC}_{3}{ }^{+} \mathrm{NBTaC}_{3}{ }^{-}$ \\
\hline Chronic pneumonia in adults & $\mathrm{CD}_{3}{ }^{-} \lg \mathrm{A}_{2}^{-} \lg \mathrm{M}_{2}^{-}$ & Purulent soft tissue infection & $\mathrm{CD}_{3}{ }^{+} \mathrm{E}_{3}{ }^{+} \mathrm{CD} 19_{2}^{-}$ \\
\hline Chronic pneumonia in children & $\mathrm{CD}_{2}{ }^{-} \mathrm{CD} 19_{2}{ }^{-} \operatorname{lgM}_{2}^{-}$ & Acute salping-oophoritis & $\mathrm{L}_{3}{ }^{+} \mathrm{ClC}_{3}{ }^{+} \mathrm{CD}_{2}{ }^{-}$ \\
\hline Exogenous bronchial asthma & $\mathrm{CD}_{2}{ }^{-} \mathrm{CD} 19_{2}{ }^{-} \lg \mathrm{A}_{2}{ }^{-}$ & $\begin{array}{l}\text { Exacerbation of chronic } \\
\text { salping-oophoritis }\end{array}$ & $\mathrm{Tc}_{3}{ }^{+} \mathrm{IL}_{3}{ }^{+} \mathrm{T}_{3}{ }^{+}$ \\
\hline Endogenous bronchial asthma & $\mathrm{Lph}_{2}{ }^{+} \mathrm{CD}_{2}{ }^{-} \mathrm{CD}_{2}{ }^{-}$ & Acute pyelonephritis & $\operatorname{lgG}_{3}{ }^{+} \mathrm{MWM}_{3}{ }^{+} \mathrm{L}_{2}{ }^{+}$ \\
\hline $\begin{array}{l}\text { Mixed bronchial asthma in } \\
\text { adults }\end{array}$ & $\mathrm{SN}_{2}{ }^{+} \mathrm{CD} 32^{-} \mathrm{NBTs}_{2}^{+}$ & $\begin{array}{l}\text { Exacerbation of chronic } \\
\text { pyelonephritis }\end{array}$ & $\mathrm{ESR}_{3}{ }^{+} \operatorname{lgG}_{3}{ }^{+} \mathrm{CD}_{3}{ }^{+}$ \\
\hline $\begin{array}{l}\text { Mixed bronchial asthma } \\
\text { in children }\end{array}$ & $\mathrm{CD}_{3}{ }^{-} \mathrm{CD} 4_{2}{ }^{-} \mathrm{CD} 8_{2}{ }^{-}$ & $\begin{array}{l}\text { Exacerbation of calculous } \\
\text { pyelonephritis }\end{array}$ & $\mathrm{CD}_{4}{ }^{-} \mathrm{CD}_{2}{ }^{-} \mathrm{PI}_{2}^{-}$ \\
\hline $\begin{array}{l}\text { Corticosteroid bronchial asthma } \\
\text { in adults }\end{array}$ & $\mathrm{CD}_{3}{ }^{-} \mathrm{CD} 19_{2}{ }^{-} \lg \mathrm{A}_{3}^{-}$ & $\begin{array}{l}\text { Exacerbation of non-calculous } \\
\text { pyelonephritis }\end{array}$ & $\mathrm{CD} 8_{2}^{-} \mathrm{CD} 19_{2}^{-}{ }^{-} \mathrm{CD} 3_{2}$ \\
\hline $\begin{array}{l}\text { Exacerbation of mixed bronchial } \\
\text { asthma }\end{array}$ & $\mathrm{L}_{2}{ }^{+} \mathrm{CD}_{4}{ }^{-} \mathrm{CD}_{3}{ }^{-}$ & & \\
\hline $\begin{array}{l}\text { Remission of mixed bronchial } \\
\text { asthma }\end{array}$ & $\mathrm{SN}_{3}{ }^{+} \mathrm{CD} 19_{2}{ }^{-} \mathrm{MWM}_{2}{ }^{+}$ & $\begin{array}{l}\text { Exacerbation of chronic } \\
\text { salping-oophoritis + cervicitis }\end{array}$ & $\mathrm{E}_{3}{ }^{+} \mathrm{CD}_{2}{ }^{-} \mathrm{CD}_{2}{ }^{+}$ \\
\hline Chronical bronchitis & $\mathrm{CD}_{4}{ }^{-} \mathrm{CD}_{3}{ }^{+} \mathrm{ClC}_{3}{ }^{+}$ & & \\
\hline $\begin{array}{l}\text { Chronic obstructive pulmonary } \\
\text { disease }\end{array}$ & $\mathrm{CD}_{2}{ }^{-} \mathrm{CD} 19_{2}{ }^{-} \lg \mathrm{A}_{3}^{-}$ & Cervicitis & $\mathrm{CD}_{2}{ }^{-} \mathrm{CD} 19_{2}{ }^{-} \lg \mathrm{A}_{2}^{-}$ \\
\hline $\begin{array}{l}\text { Infectious destruction } \\
\text { of the lungs }\end{array}$ & $\mathrm{CD}_{3}{ }^{-} \mathrm{CD} 19_{2}^{-} \lg \mathrm{A}_{2}^{-}$ & Exacerbation of chronic cystitis & $\operatorname{lgG}_{3}{ }^{+} \mathrm{NBTac}_{3}{ }^{-} \mathrm{TNF}_{3}{ }^{+}$ \\
\hline
\end{tabular}

Legend: CD3- CD3+ lymphocytes (Lph), CD19- CD19+ B-Lph, SN- stab neutrophils, NBTsp-spontaneous test with nitro blue tetrazolium, L- leucocytes, MWM-medium-weight molecules, NBTac- active test with nitro blue tetrazo-

lium, CIC- circulating immune complexes, IL- interleukin, E- eosinophil, ESR- erythrocyte sedimentation rate, PI- phagocytic index, TcT-cytotoxic Lph, TNF- tumornecrosis factor, ISDF- Immune System Disorders Formula (3 parameters most different from the normative level). Explanation of abbreviations oxidative markers -in the text: NPT- non-protein thiols, DC- diene conjugates, SB-Schiff's base, ARA- arabinose - a factor of free radical oxidation

in the body

\section{TABLE 4: The ratio of decreased and increased parameters in children with asphyxia}

\begin{tabular}{|c|c|c|c|c|}
\hline $\begin{array}{l}\text { Groups of sick and } \\
\text { healthy }\end{array}$ & ISDF & $\begin{array}{l}\text { Clinical outcomes of } \\
\text { myocardial infarction }\end{array}$ & $\begin{array}{l}\text { Number of } \\
\text { reduced parameters }\end{array}$ & ISDF \\
\hline $\begin{array}{l}\text { Newborns with } \\
\text { asphyxia }\end{array}$ & $\mathrm{NK}_{2}^{-} \mathrm{Ma}_{3}{ }^{+} \mathrm{IgM}_{3}^{-}$ & 1. Saccular aneurysm & 6 & $\operatorname{lgG}_{1}{ }^{-} \mathrm{Th}_{2}{ }^{+} \mathrm{ClC}_{2}{ }^{+}$ \\
\hline $\begin{array}{l}\text { Children with } \\
\text { asphyxia ( } 4-5 \text { days) }\end{array}$ & $\mathrm{B}_{2}^{-} \mathrm{NK}_{2}^{-} \lg \mathrm{M}_{2}^{+}$ & $\begin{array}{l}\text { 2. Saccular aneurysm } \\
\text { with dilation }\end{array}$ & 4 & $\mathrm{Tc}_{2}{ }^{-} \operatorname{lgG}_{1}{ }^{+} \mathrm{ClC}_{2}{ }^{+}$ \\
\hline Kids on ALV & $\mathrm{B}_{2}{ }^{-} \mathrm{Tc}_{2}{ }^{-} \mathrm{NBTsp_{2 }}{ }^{-} \lg \mathrm{G}_{3}^{-}$ & $\begin{array}{l}\text { 3. Diastolic } \\
\text { dysfunction }\end{array}$ & 10 & $\mathrm{Th}_{2}{ }^{-} \mathrm{ClC}_{2}{ }^{-} \mathrm{SI}_{2}^{+}$ \\
\hline Healthy newborns & $\mathrm{B}_{3}{ }^{+} \mathrm{NK}_{2}{ }^{+} \mathrm{Th}_{2}{ }^{+} \mathrm{NK}_{2}^{-}$ & 4. Progressive dilation & 8 & $\mathrm{Sl}_{2}{ }^{+} \mathrm{Th}_{2}{ }^{+} \mathrm{ClC}_{2}{ }^{+}$ \\
\hline $\begin{array}{l}\text { Healthy children } \\
\text { (4-5 days) }\end{array}$ & $\mathrm{NBTac}_{2}{ }^{-} \mathrm{NBTSp}_{2}{ }^{-} \mathrm{NK}_{2}{ }^{+}$ & $\begin{array}{l}\text { 5. Compensated } \\
\text { hemodynamics }\end{array}$ & 18 & $\mathrm{Th}_{2}^{-}{ }^{-} \mathrm{Tc}_{2}{ }^{-} \mathrm{B}_{2}^{-}$ \\
\hline
\end{tabular}

Legend:NK- natural killer cells, Ma- CD95+ lymphocytes (Lph), Th- T-helper, NBTac-active test with nitro blue tetrazolium, SIsuppression index, B- B-Lph, ALV- artificial lung ventilation, * reliability of differences $\mathrm{P}<0.05$ 


\section{INNOVATIVE JOURNAL}

a negative factor, since it was associated with a decrease in anti-infectious resistance and an increase in morbidity in newborns.

During the immune examination of patients with primary myocardial infarction, other data were obtained (Table 4). ${ }^{12}$

In patients 10-15 days after transmural myocardial infarction, the number of significantly different routine immune parameters from the normative level in healthy individuals was assessed. Using the coefficient of diagnostic value, the ISDF support terms were determined at this time, and after 12 months these data were compared with six variants of clinical outcomes of the disease in terms of compensated and uncompensated hemodynamics. It was shown that the number of suppressed immune makers (18 and $10)$ in the acute period of myocardial infarction, in groups of patients No. 5 and 3, was higher than in individuals with pathological remodeling (respectively 8, 6 and 4 in groups No. 4, 1, 2), with a complicated course of reparative processes in the myocardium. Analysis of ISDF signaling markers in patients with a successful outcome of the disease showed a decrease in the level of regulatory subpopulations of T-cells, B-lymphocytes, CIC, and stimulation of the suppression index. In other cases, where the activation of the parameters of the immune system was recorded, the clinical condition of the patients was worse.

Thus, suppression of immune reactivity in the acute period of myocardial infarction turned out to be a positive factor in improving the quality of life of patients. ${ }^{6}$

There is a certain phasing in the activation/suppression of antibacterial and antiviral immunity. Thus, it is known that inoculation stimulation of the formation of antibacterial antibodies is associated with a temporary decrease in antiviral resistance, which is expressed by an increase in the incidence of acute respiratory viral infections, and in viral infections (influenza), the opposite picture of the activation of antiviral and suppression of bacterial immunity with corresponding complications is observed.

The effects of stimulation or suppression of immune responses were found to be dependent on the strength of antigenic stimulation. Thus, small doses of anti- gens induced hypersensitivity or immune memory, "medium" doses of an effector response and immune memory, and large doses, respectively, induced immune paralysis. ${ }^{10}$ As is known, the theory of the Erne-Richter network ${ }^{2}$ is built on these mechanisms, which consists in the fact that low concentrations of antigens cause low-gap tolerance (suppression of the immune response), average optimal response (stimulation), and high high-zone tolerance (suppression).

\section{2 | CONCLUSION}

When analyzing the literature data and the results of examining patients with a wide range of pathological processes, it was found that polar changes in reactivity provoke the development of immunedependent (primary and secondary deficits, autoaggressive and immunocomplex) or immunoassociated (purulent-inflammatory diseases, nonspecific inflammatory lung diseases, cerebrovascular diseases, and other diseases), diseases in which suppression and stimulation of reactivity is a pathogenetic mechanism for normalizing homeostasis, depending on the links of the immune system, doses of antigens, the initial state of protective functions, phases of the immune response, etc.

\section{REFERENCES}

1. Zemskov AM, Zemskov VM, Korotkikh IN, Zemskov MA, Korotkikh N. Moscow. Publishing House: Triada-X; 2007.

2. Zemskov AM, Zemskov VM, Chereshnev V. Encyclopedia of Immunology in 5 volumes. Triada-X. 2013;p. 1962-1962.

3. Zemskov AM, Zemskov VM, Zemskova V. Moscow. Publishing House: Triad X; 2015.

4. Zemskov AM, Esaulenko IE, Chereshnev VA, Zemskov VM, Suchkov SV, Zemskova VA. Course of lectures on Immunophysiology. Textbook. Voronezh. Limited Liability Corporation: Publishing House: Ritm; 2017. p. 1048-1048. 
5. Khaitov RM, Immunology; 2011.

6. Zemskov AM, Zemskov VM, Esaulenko I. New principles of assessment and correction of immunological disorders. Triada-X. 2008;p. 336336.

7. Zemskov VM, Zemskov AM, Pronko K. General representations about immunopatological state. Internat J Case Study;2020(7):12-21.

8. Bugrym N. Features of cellular and humoral immunity in newborns who have undergone severe asphyxia. Dis. ... Candidate of medical sciences. Voronezh; 2011.

9. Khaitov RM, Ignatieva GA, Sidorovich IG, Immunology. Moscow. Publishing House: Medicine; 2010.

10. Novikov DK, Novikov PD, Clinical immunopathology. Moscow. Publishing House: Medical Literature. 2009
11. Zemskov AM, Zemskova VA, Popov VI, Karaulov AV, Konoplya AI, Immunology. Voronezh. Publishing House: Scientific Book; 2013.

12. Zemskov AM, Esaulenko IE, Chereshnev VA, Zemskov VM, Suchkov SV, Kozlov VA, et al. Immunology. Electronic Textbook for Students of Medical Higher Education Institution and Faculties with Applications. Moscow. Publishing House: GEOTAR-Media, 265 author's pages. 2016.

How to cite this article: Zemskov V.M., Zemskov A.M., Neymann V., K.N.P., A.A.B., V.A.Z., M.N.K., N.S.S., V.S.D., A.A.A. CONTRADICTION TO CLINICAL IMMUNOLOGY. SUPPRESSION AND STIMULATION OF IMMUNE REACTIVITY IN PATHOLOGICAL PROCESSES. Innovative Journal of Medical and Health Science. 2021;1656-1664. https://doi.org/ 10.15520/ijmhs.v11i05.3286 